\title{
The ten decrees of nanomaterials regulations
}

\section{Clausen, Lauge Peter Westergaard; Hansen, Steffen Foss}

\section{Published in:}

Nature Nanotechnology

Link to article, DOI:

10.1038/s41565-018-0256-2

Publication date:

2018

Document Version

Peer reviewed version

Link back to DTU Orbit

Citation (APA):

Clausen, L. P. W., \& Hansen, S. F. (2018). The ten decrees of nanomaterials regulations. Nature Nanotechnology, 13(9), 766-768. https://doi.org/10.1038/s41565-018-0256-2

\section{General rights}

Copyright and moral rights for the publications made accessible in the public portal are retained by the authors and/or other copyright owners and it is a condition of accessing publications that users recognise and abide by the legal requirements associated with these rights.

- Users may download and print one copy of any publication from the public portal for the purpose of private study or research.

- You may not further distribute the material or use it for any profit-making activity or commercial gain

- You may freely distribute the URL identifying the publication in the public portal

If you believe that this document breaches copyright please contact us providing details, and we will remove access to the work immediately and investigate your claim 
The Ten Decrees of Nanomaterials Regulations

The new revisions of the annexes of the European Union's chemical legislation with regards to nanomaterials will provide more structure and clarity, but they will also force manufacturers, importers and down-stream users to put substantial effort in understanding the details what should and should not be done.

Lauge Peter Westergaard Clausen ${ }^{\mathrm{a}}$, Steffen Foss Hansen ${ }^{\mathrm{b}}$

Department of Environmental Engineering, Technical University of Denmark, Miljoevej Building

11 115, DK-2800 Kgs. Lyngby, Denmark.

12 a) e-mail: 1pwc@env.dtu.dk

b) e-mail: sfha@env.dtu.dk

In April of 2018, European Member States approved the European Commission's draft Regulation revising the Annexes of the Union's chemical legislation with regard to nanomaterials ${ }^{1,2}$. The chemical legislation currently includes 17 Annexes that specify many of the technical and scientific details of the legislation and the criteria for when, how and what different actors such as manufacturers, importers, down-stream users, regulatory authorities have to do - and not do - with regard to registration and chemical safety assessment. Hence, the Annexes play an significant role

21 in the practical implementation of the legal prerequisites outlined in the main legal text. The draft

22 had been out for public consultation in the fall of 2017 and the Regulation has now been adopted by

23 the European Commission after a three-month scrutiny review of the European Parliament and

24 Council $^{3}$. The Annex revisions, that aim to clarify registration duties for nanomaterials, come after 25 years of discussion between European Commission, EU Member States and other stakeholders. 
In this commentary, we introduce and discuss the new obligations that manufacturers,

27 importers and downstream users "shall" comply with before this Regulation applies from 1 January 282020.

29

\section{Thou shalt register and demonstrate safety}

31 In essence, we summarize the new Annex revisions into ten decrees aiming at making 32 manufacturers, importers and down-stream users register "nanoforms" and demonstrate safety of all 33 their uses (see table 1). 


\section{Degree}

1. Thou shalt register nanoforms and provide information on characteristics that may influence (eco)toxicity and environmental exposure.

2. Thou shalt not use molecular structural similarities alone as a justification for grouping different nanoforms.

3. Thou shalt justify why safety information provided is relevant for all registered nanoforms.

4. Thou shalt document safety for all registered nanoforms along the life-cycle.

5. Thou shalt provide information of test conditions and nanoforms tested.

6. Thou shalt fulfil specific ecotoxicity related test requirements for different nanoforms depending on their dissolution and solubility

7. Thou shalt fulfil specific toxicity related test requirements for different nanoforms depending on their nature and likely route of exposure

8. Thou shalt consider multiple metric reporting of results for nanoforms that are dangerous or hazardous.

9. Thou shalt provide justification for waiving information requirements.

10. Thou shalt propose further testing and/or comply with ECHA testing requirements.

\section{Specific information to be provided}

- Names or other identifiers of the nanoforms or sets of similar nanoforms of the substance as part of the substance identification.

- Number-based particle number size distribution, surface functionalization or treatment, shape and aspect ratio, specific surface area by volume and/or by mass.

- Characteristics of different nanoforms within a set in the ranges of values clearly defining the boundaries of the set.

- Justification for why the sets are appropriate and why variation within the boundaries do not affect the hazard-, exposure- and risk assessment of the individual nanoforms within the set.

- Adequate justification for each information requirement describing when and how information on one nanoform is used to demonstrate safety of other forms.

- Demonstration of safety of manufacture, use and exposure to different nanoforms separately considering all stages of the life-cycle of the substance.

- Consideration of whether specific risk assessment and risk management measures are required.

- Documented test conditions and scientific justification for the relevance and adequacy of the utilised test material

- Justification of information obtained from means other than testing for the different nanoforms, including a description of the range of the characteristics of the nanoforms to which the evidence can be applied.

- Assessment of potential confounding effect of dispersion when determining water solubility and partition coefficient n-octanol/water.

- Consideration of long-term aquatic toxicity studies instead of short-term studies if the substance is poorly water soluble or for nanoforms with a low dissolution rate in relevant test media.

- Acute toxicity study for the oral route or the inhalation route and at least one other route for substances manufactured or imported in 10 tonnes or more per year

- Consideration of toxicokinetics, including recovery period and, where relevant, lung clearance in the short-term repeated dose toxicity study and the sub-chronic toxicity study.

- Complete exposure assessment and risk characterization preferably considering a multiple metric presentation of the results.

- Justification included in the Chemical Safety Report and summarised in the Safety Data Sheet.

- Adequate justification for relevance of physicochemical property (e.g. dissolution rate, dispersion stability) as reason for waiving tests on bioaccumulation in aquatic species and adsorption/desorption.

- Testing proposals regarding short-term repeated dose toxicity studies, studies of sub-chronic toxicity and long-term repeated dose toxicity studies and toxicokinetic studies in specific situations. 
Under the European chemical legislation, manufacturers and importers have to register their substances, if produced in quantities of 1 tonne or more per year. According to the new Regulation, specific minimum characterisation information, such as number-based particle number size distribution, shall be provided by the registrant for "nanoforms" as these characteristics may influence its (eco)toxicological profile and environmental exposure.

Nanoforms are defined as a form of a natural or manufactured substance containing particles, in an unbound state or as an aggregate or as an agglomerate and where, for $50 \%$ or more of the particles in the number size distribution, one or more external dimensions is in the size range $1 \mathrm{~nm}-100 \mathrm{~nm}^{2}$. The information provided by the registrant may be applicable to an individual nanoform or a set of similar nanoforms and grouping of nanoforms is possible, if justification is provided. Notably, molecular structural similarities alone cannot serve as a justification. For general registration purposes, the revised Annexes requires that information on manufacture and use provided in the registration for regular substances shall also apply to nanoforms or sets of similar nanoforms including tonnage used, concentration range used, quantities in articles, human and environmental exposure and waste quantities and composition ${ }^{2}$. When registrants of nanoforms submit joint registration dossiers, they shall justify why information provided is relevant for nanoforms or they may submit relevant information separately ${ }^{2}$.

The number of decrees and use of the word "shall" is no more outspoken in the revised Annexes than in sections related to the Chemical Safety Report that has to be provided for substances manufactured or imported in a quantity of 10 tonnes or more per year. According to the new Annexes, the Chemical Safety Report shall first specify whether and which different nanoforms have been characterised as part of the registration and are covered by the Chemical Safety Assessment. Interestingly, this also applies to producers and importers of articles that are required to prepare a Chemical Safety Assessment as part of their registration ${ }^{2}$. Second, registrants 
shall describe how information is compiled, document adequately control of risks associated with the uses of their nanoforms and ensure that justifications and conclusions are relevant to these nanoforms along the life-cycle of the substance.

As a general requirement, the nanoform tested shall be appropriately characterised and test conditions documented to allow for adequate assessment of the relevance of any physicochemical, toxicological and ecotoxicological information provided for the different nanoforms ${ }^{2}$. In case, the nanoforms of a substance fulfil the criteria for dangerous or hazardous substances, an exposure assessment and risk characterization shall be completed using an appropriate metric and preferably considering a multiple metric presentation of the results. It is furthermore repetitively mentioned as a general requirement with regard to classification and labelling, that registrants shall indicate and justify actions or decisions taken if information is inadequate to classify a substance and nanoforms thereof for a particular hazard class or category ${ }^{2}$.

When it comes to fulfilling specific information requirements as part of the Chemical Safety Assessment, the revised annex entail a number of very specific decrees. For instance, for nanoforms that are not soluble nor have high dissolution rate, further degradation tests shall consider morphological transformation e.g. irreversible changes in particle size, shape, surface properties, loss of coating, chemical transformation and other abiotic degradation ${ }^{1,2}$. A range of studies do not need to be conducted depending on the specific circumstances e.g. dustiness does not need to be reported, if exposure to granular form of the substance during its life-cycle can be excluded $^{2}$. It is important that registrants note that high insolubility in water cannot serve as a justification for waiving of a number of information requirements related to the environment e.g. for short-term toxicity testing on invertebrates and growth inhibition studies of aquatic plants.

In some aspects, the Annex revisions is very inclusive. In the assessment of persistency, bioaccumulation and toxicity, registrants have to consider all stages of the life-cycle when making 
quantitative and qualitative estimates of the dose/concentration of the substance to which humans and the environment are or may be exposed to. This includes estimating environmental distribution and fate and performing a characterisation of possible degradation, transformation, reaction processes, dissolution rate, particle aggregation and agglomeration and changes in particle surface chemistry.

The Annex also holds several decrees with respect to further testing. For instance, further studies shall be proposed by the registrant or may be required by the European Chemicals Agency (ECHA) for toxicokinetic studies with regard to nanoforms with high dissolution rate in biological media and for specific additional particle properties "reasonable suspected" to markedly alter the hazard or exposure of the nanoforms of concern.

When downstream users deem additional information necessary for the completion of the Chemical Safety Report, they shall gather the needed information and/or submit a testing strategy proposal, if the required information is pivotal and only obtainable by vertebrate experiments. If waiting for test results, downstream users shall record and ensure relevance of their risk management measures intended to manage the risk for all nanoforms used by the user and any identified nanoforms used further downstream in the supply chain.

\section{The devil(s) in the detail}

The Commission, EU Member States and stakeholders involved in the process of revising the Annex deserve credit for making it clear that different nanoforms of a substance have to be registered individually or as groups, outlining the Chemical Safety Assessment procedures to be followed and finally, clarifying when specific information requirements have to be addressed for nanoforms and when these can and cannot be waived. 

facets left to them to decide upon and that the devil(s) lies in the details of many of the decrees outlined in table 1.

First, manufacturers and importers have to decide whether they have nanoforms that need to be registered and for which, data on e.g. particle size distribution, surface functionalization or treatment and shape and aspect ratio has to be provided. In order to determine whether a nanoform

111 is produced or imported, the number-based particle size distribution has to be characterised, but 112 generally agreed methods and technical standards on how to measure particle size distribution are 113 not yet available ${ }^{4}$. Different methods often provide different results within and outside the size 114 range of $1 \mathrm{~nm}-100 \mathrm{~nm}$ for the same material. This leaves manufacturers and importers in a 115 dilemma having to choose between methods that either show that their materials are not 116 nanomaterials thereby avoiding any registration and Chemical Safety Assessment obligations or 117 choosing another method that identifies their materials as a nanomaterial, subsequently having to 118 meet a whole range of scientifically and technically challenging registration and test requirements. 119 It is well known that particle size is linked strongly to the manufacturing process ${ }^{5}$. Hence, it could 120 be clearer specified in the Annex that a combination of methods have to be applied along with a 121 description of the applicability of the chosen methods, sample preparation and the nanomaterial 122 production process $^{6}$. Further complicating matters, there is an on-going process to evaluate the 123 nanomaterial definition proposed by the European Commission back in 2011 as this definition 124 leaves a lot of room for interpretation of terms such as "particle," "size" and "external dimension" 125 Updates to the definition were expected in mid- $2016^{8}$, but has yet to be put forward which creates 126 regulatory uncertainty and confusion about what a new definition might look like. 
information they subsequently have to provide in the registration dossiers and in the Chemical

130 Safety Report. The revised Annex clearly state that molecular structural similarities cannot be used

131 alone as a justification for grouping different nanoforms, but it varies in regard to the nature of 132 explanation and justification that has to be provided. With regard to registration a "justification" has 133 to be provided for why grouping and sets of nanoforms are appropriate and for why the variation 134 within the boundaries of a set do not affect the hazard-, exposure- and risk assessment, whereas a 135 so-called "scientific justification" shall be provided in cases, where the registrant wishes to use data 136 from one nanoform in the demonstration of the safe use of other nanoforms. ECHA does provide 137 guidance on grouping of nanoforms making it clear that correct and unambiguous characterisation 138 of the nanoforms is a prerequisite for grouping. This raises the question of how manufacturers and 139 importers are to provide "justification" for forming sets of nanoforms and subsequently not having 140 to provide characterization of all registered nanoforms, when unambiguous characterization of the 141 nanoforms in the first place is considered a prerequisite by ECHA. The second ECHA prerequisite 142 is the development of a grouping hypothesis and a robust scientific justification, including that the 143 hazard characterization is valid for all nanoforms within the group. Three examples of hypotheses 144 provided by ECHA are hypothesis based on solubility, high aspect ratio and impact of surface 145 treatment on grouping 9 . Here again it seems that the only manner in which manufacturers and 146 importers can truly provide "scientific justification" of grouping with regard to e.g. hazard 147 characterization and demonstrate safety is by generating information for all registered nanoforms. Many of the test specific requirements are hung on vague terms such as "poorly soluble", 149 "high insolubility" and "low" versus "high" dissolution rate. This is a third important aspect that 150 manufacturers and importers have to be alert to. It is well-established that nanomaterials do not go 151 into solution, but are dispersed ${ }^{10,11}$ and as these terms are not clearly defined in the Annex, whether 152 specific test requirements have to be meet will depend on how the registrant interprets such terms. 
153 Furthermore, the technical guidance that ECHA currently provides to registrants on how to meet 154 specific test requirements for nanomaterials entail no assistance on how to measure and report on, 155 for instance, irreversible transformations in particle size, shape, surface properties and loss of 156 coating considering all stages of the life-cycle and with regard to assessing the environmental 157 distribution and fate $12,13,14,15$. The revised Annex provided a great opportunity for the European Commission to clarify EU 159 chemical registration duties for nanomaterials and resolve the regulatory uncertainty that has 160 plagued the development and commercialization of nanomaterials since EU's new chemical 161 legislation was adopted in $2006^{16}$. This opportunity was arguably not fully taken advantage of and 162 there are issues with regards to characterization of nanoforms, grouping of nanoforms and when it 163 is necessary to fulfil specific information requirements that manufacturers, importers and 164 downstream-users have to be aware of when trying to comply with the new regulation.

${ }^{1}$ COMMISSION REGULATION (EU) .../... of XXX amending Regulation (EC) No 1907/2006 of the European Parliament and of the Council on the Registration, Evaluation, Authorisation and Restriction of Chemicals (REACH) as regards Annexes I, III, VI, VII, VIII, IX, X, XI, and XII to address nanoforms of substances (European Commission 2018);

http://ec.europa.eu/transparency/regcomitology/index.cfm?do=Search.getPDF\&ds id=56122\&version=2\&AttLang=en $\& \mathrm{db}$ number $=1 \&$ docType $=$ DRAFT MEASURE

${ }^{2}$ ANNEX (European Commission, 2018); http://ec.europa.eu/transparency/regcomitology/index.cfm?do=Search.getPDF\&ds id=56122\&version=2\&AttLang=en $\& \mathrm{db}$ number $=2 \&$ docType $=$ DRAFT MEASURE

${ }^{3}$ REACH: Member States vote for more clarity in nanomaterials registrations. (European Commission, 2018); http://ec.europa.eu/environment/chemicals/news_en.htm

${ }^{4}$ Roebben, G. et al. Towards a review of the EC Recommendation for a definition of the term "nanomaterial" Part 2: Assessment of collected information concerning the experience with the definition (European Commission Joint Research Centre, 2014); http://publications.jrc.ec.europa.eu/repository/bitstream/JRC91377/jrc_nmdef_report2_eur26744.pdf

${ }^{5}$ Christensen, F.M. et al. NANO SUPPORT (European Commission

Joint Research Centre, 2012); http://ec.europa.eu/environment/chemicals/nanotech/pdf/jrc_report.pdf 
${ }^{6}$ Hansen, S.F. Registration, Evaluation, Authorisation, Categorisation and Tools to Evaluate Nanomaterials - Opportunities and Weaknesses (REACT NOW) (DTU, 2018); http://orbit.dtu.dk/files/147141535/19 04_2018_REACT_NOW_SFH.pdf

${ }^{7}$ Rauscher et al. Towards a review of the EC

Recommendation for a definition of the term "nanomaterial": Part 3: Scientific-technical evaluation of options to clarify the definition and to facilitate its implementation. (European Commission Joint Research Centre, 2015);

http://publications.jrc.ec.europa.eu/repository/bitstream/JRC95675/towards\%20review\%20ec\%20rec\%20def\%20nanom aterial $\% 20-\% 20$ part $\% 203$ report_online $\% 20 \mathrm{id} . \mathrm{pdf}$

${ }^{8}$ Roberts, G. Commission rejects idea of EU nano register. Chemical Watch (2016); https://chemicalwatch.com/45776/commission-rejects-idea-of-eu-nano-register

${ }^{9}$ Appendix R.6-1 for nanomaterials applicable to the Guidance on QSARs and Grouping of Chemicals Version 1.0 (ECHA 2017); https://echa.europa.eu/documents/10162/23036412/appendix_r6_nanomaterials_en.pdf/71ad76f0-ab4cfb04-acba-074cf045eaaa

${ }^{10}$ Skjolding, L.M., Sørensen, S.N., Hartmann, N.B., Hjorth, R., Hansen, S.F., Baun, A. Angew. Chem. Int. Ed. Engl. 55, 15224-15239 (2016).

${ }^{11}$ Hartmann et al. J Toxicol Environ Health B Crit Rev. 18, 299-326 (2015).

${ }_{12}$ Appendix R7-1 for nanomaterials applicable to Chapter R7a Endpoint specific guidance Version 2.0 (ECHA 2017);

https://echa.europa.eu/documents/10162/13632/appendix_r7a_nanomaterials_en.pdf/1bef8a8a-6ffa-406a-88cdfd800ab163ae

${ }^{13}$ Appendix R7-1 for nanomaterials applicable to Chapter R7b Endpoint specific guidance Version 2.0 (ECHA 2017);

https://echa.europa.eu/documents/10162/13632/appendix_r7b_nanomaterials_en.pdf/6eca425a-ede1-4c9e-8151af77973caf32

${ }^{14}$ Appendix R7-2 for nanomaterials applicable to Chapter R7c Endpoint specific guidance Version 2.0 (ECHA 2017);

https://echa.europa.eu/documents/10162/13632/appendix_r7c_nanomaterials_en.pdf/c2d8e0ce-2ab4-4035-a05fe2dec $924 \mathrm{~d} 87 \mathrm{a}$

${ }^{15}$ Chapter R.11: PBT/vPvB assessment Version 3.0 (ECHA 2017);

https://echa.europa.eu/documents/10162/13632/information_requirements_r11_en.pdf/a8cce23f-a65a-46d2-ac68$92 \mathrm{fee} 1 \mathrm{fge} 54 \mathrm{f}$

${ }^{16}$ Bowman, D.M., van Calster, G., Friedrichs, S. Nat. Nanotech. 5, 92 (2010). 